Science, Technology and Development 34 (2): 74-81, 2015

ISSN 0254-6418 / DOI: 10.3923/std.2015.74.81

(C) 2015 Pakistan Council for Science and Technology

\title{
Effect of Dexamethasone on Phenotyping of Dendritic Cells: In vitro and in vivo Study
}

\author{
${ }^{1}$ E.A. El-Zamarany, ${ }^{2}$ N.E. El-Ashmawy, ${ }^{3}$ M.L. Salem, ${ }^{2}$ H.A. El-Bahrawy and ${ }^{2}$ G.M. Al-Ashmawy \\ ${ }^{1}$ Department of Clinical Pathology, Faculty of Medicine, \\ ${ }^{2}$ Department of Biochemistry, Faculty of Pharmacy, \\ ${ }^{3}$ Department of Immunology, Faculty of Science, Tanta University, Egypt
}

\begin{abstract}
Background: Glucocorticoids are known to suppress the immune response and are widely used as immunosuppressive agents in the treatment of many autoimmune and allergic diseases. Aim: This study investigated the effect of the steroid dexamethasone (DEX) on maturation and differentiation of DCs derived from monocytes. In addition, an in vivo experiment was conducted to investigate whether treatment of mice with DEX has immunomodulatory effect on murine splenic DCs. Methods: In vitro experiment: Immature DCs were generated by incubating peripheral blood monocytes with cytokine cocktail (GM-CSF+IL-4) for 9 days. Phenotypic analysis of the DCs' specific cell marker CD83 was performed by flow cytometry. In vivo experiment: Mice were randomly divided into 5 groups according to the dose of i.p., injection of DEX and duration of treatment. The murine splenic DCs were isolated and phenotyped for CD83 and CD11c by flow cytometry. Results: Addition of $1 \mu \mathrm{M}$ DEX to the culture on day 7 or 8 resulted in a significant increase in the CD83 expression. The in vivo experiment showed that i.p. injection of DEX significantly increased the expression of CD83 on splenic DCs. Mice groups treated with a single dose of $20 \mathrm{mg} \mathrm{kg}^{-1}$ DEX showed a significant decrease of percentage of CD11 ${ }^{+} \mathrm{CD} 83^{+}$splenic DCs. Conclusion: DEX induced the DCs to be more tolerogenic both in vitro and in vivo. It could be suggested that DEX can trigger immunosuppressive effect via modulating the expression of the cell surface markers of DCs.
\end{abstract}

Key words: Dendritic cells, dexamethasone, CD83, CD11c, murine splenic cells

\section{INTRODUCTION}

Dendritic Cells (DCs) imply crucial Antigen-Pesenting Cells (APCs) that perform an essential role in the regulation of immune responses. Different DCs subsets have different functions in priming $T$ cells. The same subset of DCs may undergo different functional states during their maturation process (Gelao et al., 2014).

In their immature phase, DCs remain in the periphery wherever they are located to identify and catch antigens. Upon suffering an activating stimulus, DCs transfer to lymphoid organs like spleen and thymus where they allow captured antigens to be recognized and exposed to T cells (Trombetta and Mellman, 2005).

Furthermore, during maturation and activation, DCs change their expression of accessory molecules. For instance, MHC class I and class II characterization increased during DCs activation. Also, the accessory molecules such as CD86, CD80, CD83 and CD40 raised during the maturation stage of DCs (Wang et al., 2013). However, only a limited number of surface molecules are preferentially expressed by DCs; high-density CD83 expression serves as a marker for the human DCs characterization and maturation (Stein et al., 2013).

In response to infections, DCs advance the production of effector $\mathrm{CD} 4^{+} \mathrm{T}$ helper 1 (Th1) and $\mathrm{CD}^{+} \mathrm{T}$ cell-dominated immune replies. In addition to these effector responses, DCs can be directed to become tolerogenic and increase regulatory $\mathrm{T}$ cells (Tregs). Tregs control effector $\mathrm{T}$ cell responses, a process that is important for preservation of immune homeostasis, control of certain diseases and management of hypersensitivities (Everts and Pearce, 2014).

Signals generated by Toll-Like receptors (TLRs), cytokines, chemokines, eicosanoids, free oxygen radicals and various inflammatory mediators contribute to a signaling matrix and influence the phenotype and functional responses of DCs (Moresco et al., 2011). Although various TLRs, such as TLR3, TLR4, TLR5, TLR7 and TLR8 induce immune activation, others, e.g., TLR2 can silence immune responses through tolerance induction of DCs. The TLR2 activation induces IL-10 production, inhibits TLR7/TLR9 signaling and prevents interferon (IFN- $\alpha$ and $-\beta$ ) production (Kadowaki et al., 2001).

Induction of immunological tolerance, specific for transplant or self-antigens while maintaining reactivity to other antigens, is an important goal in transplantation medicine and autoimmunity (Hilkens et al., 2010).

Glucocorticoids are extensively used as potent immunosuppressive and anti-inflammatory drugs because of negative interference with several features of T-cell activation such as inflammatory cytokine production 
(Gustafson et al., 2010). The DEX and other glucocorticoids affect growth, differentiation and function of many cell types, such as $\mathrm{T}$ cells, macrophages, monocytes and DCs (Baschant and Tuckermann, 2010).

Here we studied, whether the addition of DEX to the culture of freshly isolated human blood monocytes at different time points could induce DCs to be tolerogenic. Immunomodulatory effect of DEX on generation and differentiation of DCs was assessed through phenotypic analysis and microscopic examination. In addition, we examined the effect of different doses of DEX given to mice on different subsets of splenic DCs through phenotypic analysis.

\section{MATERIALS AND METHODS}

Chemicals and reagents: Dulbecco's Modified Eagle Medium (DMEM) and phosphate buffered saline-Ca ${ }^{2+}$ $\mathrm{Mg}^{2+}$ free (PBS) (Biowhittaker ${ }^{\circledR}$, Belgium). Granulocyte macrophage-colony stimulating factor (GM-CSF), phycoerythrin (PE) anti-human CD83 monoclonal antibody, Fluorescence-Activated Cell Sorting (FACS) buffer and FACS lyse solution (eBioscience ${ }^{\circledR}$, Austria). Phycoerythrin hamster anti-mouse CD11c monoclonal antibody and fluorescein isothiocyanate (FITC) rat anti-mouse CD83 monoclonal antibody (ABdSerotec ${ }^{\circledR}$, USA). IL-4 (Sigma Aldrich ${ }^{\circledR}$, USA). TNF- $\alpha$ (R and D Systems ${ }^{\circledR}$, USA). Penicillin-streptomycin solution (Pen/Strep) (Euro-lone ${ }^{\circledR}$, Europe). Amphotericin B (Fungizone ${ }^{\circledR}$ ) $\left(\right.$ Gibco $^{\circledR}$, USA). Biocoll separating solution, density $1.077 \mathrm{~g} \mathrm{~mL}^{-1}$ (Biochrom ${ }^{\circledR}$, Germany). Dexamethasone (Enzolifescience ${ }^{\circledR}$, Europe). Heparin calcium (Cal-heparin ${ }^{\circledR}$ ) 5000 U (Amoun Pharmaceutical Co., Egypt). Human albumin (Zenalb ${ }^{\circledR}$ ) 20\% (Bio Products Laboratory Limited, United Kingdom). All other chemicals and reagents were of high analytical grade.

\section{In vitro experiment}

Isolation of monocytes: The present study was approved by the Research Ethics Committee of Faculty of Pharmacy, Tanta University, Egypt. Heparinized human peripheral blood was collected and mononuclear cells were isolated by Biocoll density gradient centrifugation. Peripheral blood monocytes (PBMCs) were then placed in the incubator (Shel lab ${ }^{\circledR}$, USA) and allowed to adhere for $2 \mathrm{~h}$ at $37^{\circ} \mathrm{C}$ in $5 \% \mathrm{CO}_{2}$. Non-adherent cells of peripheral blood lymphocytes were gently removed (Hashimdeen et al., 2013).

Generation of human monocyte-derived DCs: The DCs were generated according to Rubinstein et al. (2002). Briefly, purified human monocytes were cultured $\left(10^{6}\right.$ cells $\left./ \mathrm{mL}\right)$ on day 0 in DMEM medium supplemented with $100 \mu \mathrm{L}$ fungizone, $100 \mu \mathrm{L}$ Pen/Strep,
IL-4 (10 ng mL $\left.{ }^{-1}\right)$ and GM-CSF (10 ng $\mathrm{mL}^{-1}$ ) for 9 days in order to obtain immature DCs. The cells were further fed on day 3 with fresh DMEM medium (half the original medium volume containing the same concentration of cytokine cocktail). Maturation was achieved by addition of TNF- $\alpha$ (10 $\mathrm{ng} \mathrm{mL}^{-1}$ ) (Ye et al., 2006) dissolved in PBS on day 7 and kept for $48 \mathrm{~h}$. The DCs were harvested and analyzed on day 9.

Cell culture grouping: Regarding the above mentioned preparation of DCs, the cells were randomized to 5 subgroups (3 cultures each) to investigate DEX effect at different stages: Group A, No addition of DEX or TNF- $\alpha$; Group B, $1 \mu \mathrm{M}$ DEX (Bosma et al., 2008) added on day 7; Group C, TNF- $\alpha$ (10 ng $\left.\mathrm{mL}^{-1}\right)$ added on day 7+1 $\mu \mathrm{M}$ DEX on day 8; Group D, $1 \mu \mathrm{M}$ DEX added on day 7+TNF- $\alpha$ (10 ng $\left.\mathrm{mL}^{-1}\right)$ on day 8 and Group E, $1 \mu \mathrm{M}$ DEX added on day $0+\mathrm{TNF}-\alpha\left(10 \mathrm{ng} \mathrm{mL}^{-1}\right)$ on day 7 . Morphological changes of cells were examined on days 0 , 7 and 9 using inverted microscope Carl Zeiss ${ }^{\circledR}$, Germany.

Flow cytometric analysis for CD83 expression in DCs: The method followed was that described by Stetler-Stevenson and Braylan (2001). Cells were harvested and stained with fluorescence anti-human CD83 monoclonal antibody $\mathrm{PE}$ for $30 \mathrm{~min}$ at $4^{\circ} \mathrm{C}$. After incubation, the cells were washed with FACS buffer and finally suspended in $500 \mu \mathrm{L}$ FACS buffer. Harvested cells were injected using a BD FACSCalibur ${ }^{\circledR}$, USA and data was analyzed using BD CellQuest ${ }^{\circledR}$ software.

\section{In vivo experiment}

Experimental design: Male mice were purchased from the animal house of Geiza Institute of Ophthalmology, Cairo, Egypt. Animal care and experiments were conducted in accordance with institutional guidelines and with the approval of the Research Ethics Committee of Tanta Faculty of Pharmacy. All mice were 6-8 weeks old with an average weight between 20 and 25 g. Mice were maintained on normal balanced diet and housed in wire cages for one week under identical environmental conditions for adaptation.

Mice were randomly divided into five major groups ( $\mathrm{n}=10$ for each) according to the received treatment: Group A (normal control): Mice given the vehicle. Group B (low dose DEX): Mice received i.p. injection of DEX (4.5 $\mathrm{mg} \mathrm{kg}^{-1}$ day $^{-1} \times 5$ days) (Zheng et al., 2013). Group C (low dose DEX+TNF- $\alpha$ ): Mice treated as group $B$, then received i.p., injection of TNF- $\alpha\left(5 \mu \mathrm{g} \mathrm{kg}{ }^{-1}\right)$ one hour after the last injection of DEX (Jiao et al., 2014). Group D (high dose DEX): mice received single i.p. injection of DEX (20 mg kg-1 $\times 1$ day) (Fletcher et al., 2009). Group E (high dose DEX+TNF- $\alpha$ ): Mice treated as group $\mathrm{D}$, then received i.p., injection of TNF- $\alpha$ $\left(5 \mu \mathrm{g} \mathrm{kg}^{-1}\right)$ one hour after DEX injection. 
Isolation of spleen cells: Spleen cell suspension was prepared according to Nakano et al. (2001). Freshly dissected spleens were immediately pushed through a $40 \mu \mathrm{m}$ sieve by mechanical squeezing using rubber rode. The cells were resuspended in PBS, then cell suspensions were centrifuged at $250 \mathrm{~g}$ for $10 \mathrm{~min}$ at $8^{\circ} \mathrm{C}$ and supernatants were discarded. The sedimented cells (splenocytes) were resuspended in $1 \mathrm{~mL}$ PBS. Then, $100 \mu \mathrm{L}$ of cell suspension was taken and incubated for 20 min in BD FACS lysing solution for red blood cells lysis. The splenocytes were rinsed twice in FACS buffer by centrifugation at $400 \mathrm{~g}$ for $10 \mathrm{~min}$ at room temperature.

Flow cytometry of murine splenic DCs: The method followed was that described by Stetler-Stevenson and Braylan (2001). The spleen cells were stained with $10 \mu \mathrm{L}$ anti-CD83-FITC and $10 \mu \mathrm{L}$ anti-CD11c-PE. Following 30 min of incubation at $4^{\circ} \mathrm{C}$, the cells were washed twice in FACS buffer. The samples were injected to the flow cytometer and data were analyzed using BD CellQuest ${ }^{\circledR}$ software to determine the percentage of each of CD11 $\mathrm{c}^{-}$ $\mathrm{CD}^{+}{ }^{+}$and $\mathrm{CD} 11 \mathrm{c}^{+} \mathrm{CD} 83^{+}$expressing Dcs.

Statistical analysis: All statistical analyses were accomplished by using Microsoft Office Excel 2007. Differences between groups were statistically analyzed using one way analysis of variance (ANOVA). The results were expressed as Mean \pm Standard Error (S.E). p-values less than 0.05 were considered statistically significant.

\section{RESULTS}

Generation of DCs and morphological examination: The PBMCs were cultured in DMEM medium (day 0), undergone morphological change (day 3), transformed to immature DCs (day 7) and differentiated into mature DCs (day 9) (Fig. 1). Cultures to which TNF- $\alpha$ was added showed cells with no different morphology from those without TNF- $\alpha$.

Microscopically, DCs in various groups reached nearly full growth on day 7 and completely covered the culture plates on day 9, that were noted as local cell clusters. On day 9, DCs appeared to be loosely adherent and have branched projections (Fig. 2a). All cultures subjected to DEX treatment exhibited no notable changes in the morphology of DCs examined under the microscope compared with control untreated cultures (Fig. 2b).

Dexamethasone effect on phenotyping of DCs: The DCs marker CD83 was identified by flow cytometry. Dexamethasone significantly raised CD83 expression on DCs in groups B, C and D compared to the control group A. Group C showed the highest percentage of CD83 expression that increased significantly compared to other DEX treated cultures (groups B, D and E). The percentage of DCs that expressed CD83 was $27.25 \pm 0.76 \%$ in the control culture of group A, 41.66 $\pm 2.03 \%$ in culture of group $\mathrm{B}, 54.33 \pm 2.33 \%$ in culture of group C,
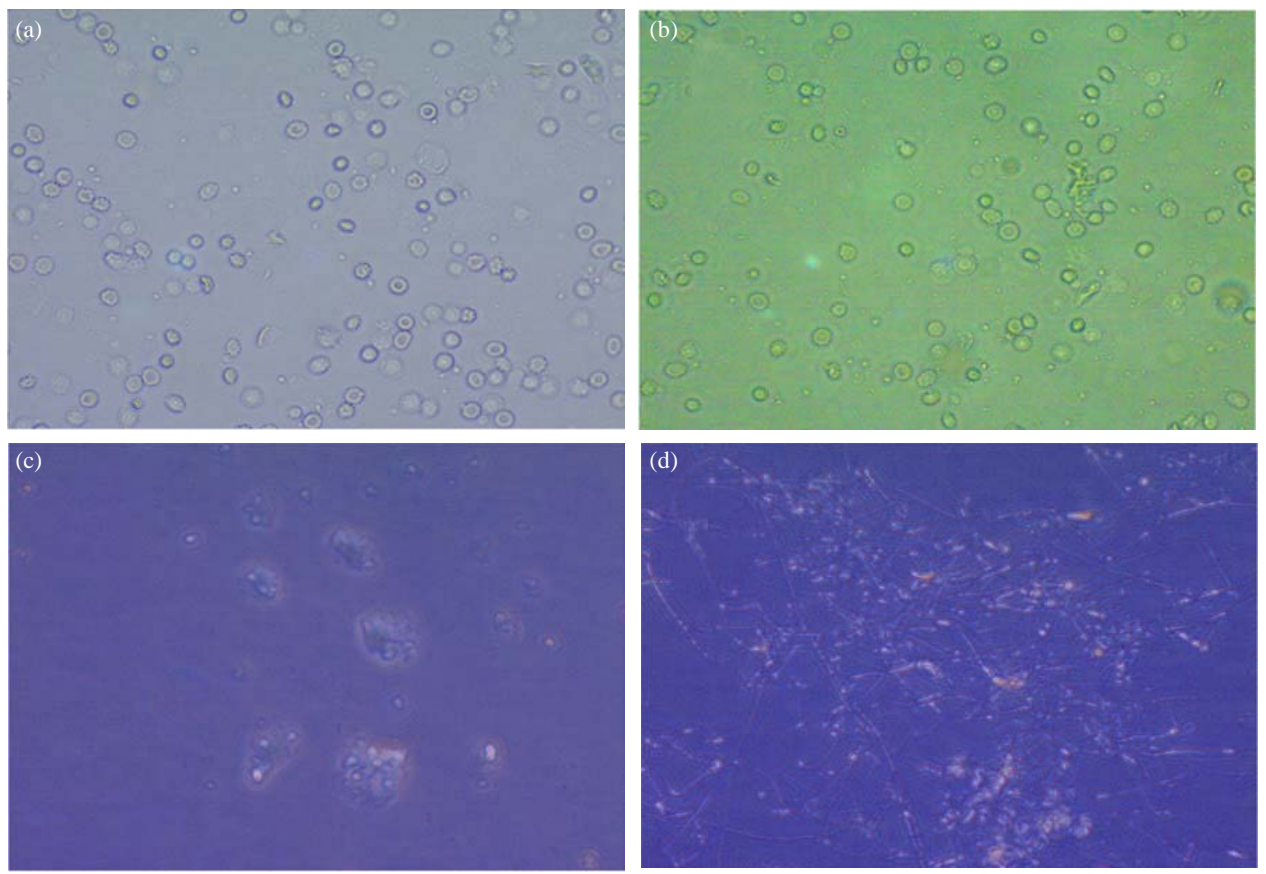

Fig. 1(a-d): Morphological changes during generation and differentiation of DCs (40x), (a) Adherent monocytes on day 0, (b) Transforming monocytes on day 3, (c) Generated DCs on day 7 and (d) Mature DCs on day 9 

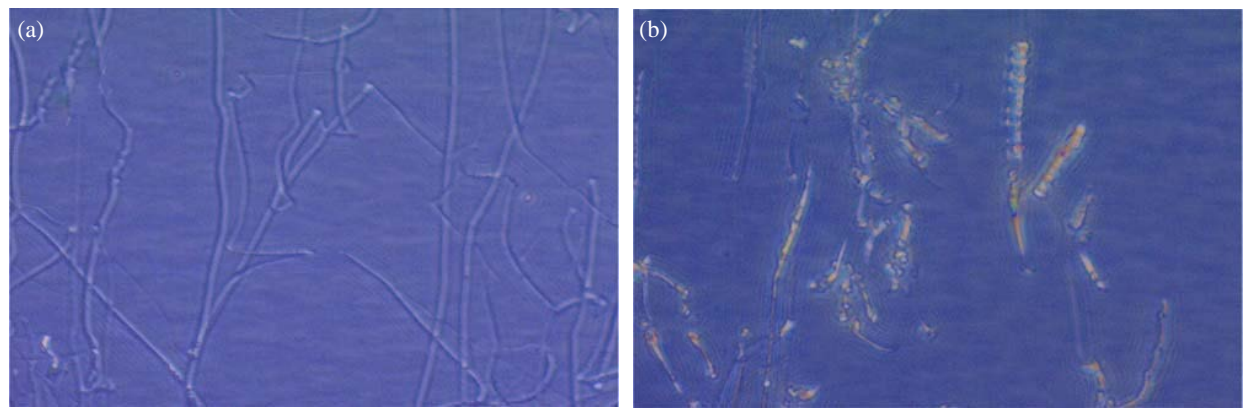

Fig. 2(a-b): Microscopic image of DCs on day 9 (100x) showing cells with branched projections, (a) DCs cells in absence of DEX and (b) DCs in presence of DEX

$37.66 \pm 1.45 \%$ in culture of group D and $22.33 \pm 1.45 \%$ in culture of group E. Treatment of monocytes with DEX on day 0 (group E) partially and insignificantly suppressed the expression of CD83 compared to control culture A (Fig. 3).

In vivo study: Because we found that $\mathrm{DEX}$ could motivate tolerogenic DCs in vitro, we examined that DEX might exert its adjuvant effect by provoking tolerogenic DCs in vivo. To test this hypothesis, the percentage of

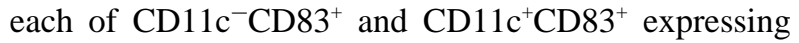
DCs was determined by flow cytometry (Fig. 4a).

The percentage of $\mathrm{CD}_{11 c^{-}} \mathrm{CD}^{+}{ }^{+}$DCs was $38.75 \pm 2.73 \%$ in the control group A, $61.33 \pm 7.84 \%$ in group $\mathrm{B}, 63.66 \pm 6.81 \%$ in group $\mathrm{C}, 89.5 \pm 0.32 \%$ in group $\mathrm{D}$ and $63.33 \pm 0.76 \%$ in group $\mathrm{E}$. The percentage of

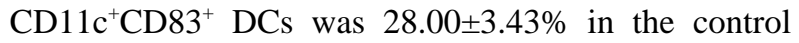
group A, $35 \pm 5.75 \%$ in group $B, 29.33 \pm 5.19 \%$ in group $C$, $13 \pm 2.87 \%$ in group $\mathrm{D}$ and $3.33 \pm 1.81 \%$ in group $\mathrm{E}$ (Fig. 4b).

The DEX-treated mice produced a significant increase in phenotypic analysis of $\mathrm{CD} 11 \mathrm{c}^{-} \mathrm{CD} 83^{+}$splenic DCs (group B, group C, group D and group E) compared to control group $\mathrm{A}$. In the presence of $\mathrm{DEX}$, these CD83-induced phenotypic changes were influenced by the dose: The up-regulation of CD83 was the largest by single high dose (20 mg kg-1, i.p.) DEX (group D) and was significant compared to control and other treated groups. However, the combination of single high dose DEX and TNF- $\alpha$ (group E) showed significant suppression of percentage of CD $11 \mathrm{c}^{-} \mathrm{CD} 83^{+}$splenic DCs compared to single high dose DEX treatment only (group D) (Fig. 4b).

Importantly, single high dose DEX-treated mice showed a significant decrease of percentage of

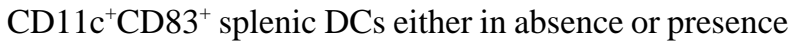
of TNF- $\alpha$ (groups D and E, respectively) compared to control group A. Moreover, the high dose DEX treated mice groups $\mathrm{D}$ and $\mathrm{E}$ showed significant lower percentage of $\mathrm{CD}_{11 \mathrm{C}^{+} \mathrm{CD}^{+}}{ }^{+}$splenic DCs compared to the corresponding low dose DEX treated groups (groups B and C, respectively) (Fig. 4b).

\section{DISCUSSION}

Studies have shown that pharmacologically-treated DCs significantly prolong the survival of transplanted organs and effectively induce immune tolerance to the transplanted organs (Demangel et al., 2002). The application of immunosuppressants to modulate DCs for tolerance induction has been postulated. Therefore, immunosuppressants could be used to develop tolerogenic DCs that can be employed for treatment of autoimmune disorders (Saito et al., 2011).

Isolation and culture of human heparinized peripheral blood buffy coats provide a valuable model for studies on DCs biology and may help uncover new means to manipulate DCs differentiation and function in therapeutic settings (Kalantari et al., 2011). In the present study, the buffy coat layer from human peripheral blood was cultured in the presence of GM-CSF and IL-4 to generate dendritic cell populations which were allowed to differentiate into mature DCs within 9 days.

The present study examined the in vitro effect of DEX on generation and differentiation of DCs through microscopic and phenotypic analysis. We demonstrated that the addition of DEX to the culture on day 0 prevented the differentiation of DCs to be tolerogenic. On the other hand, addition of DEX to the culture on day 7 or 8 , either preceded or followed by addition of TNF- $\alpha$, resulted in significant increase of CD83 expressing DCs; the greatest percent of tolerogenic DCs was obtained in the culture media to which DEX $(1 \mu \mathrm{M})$ was added on day 8 and TNF- $\alpha\left(10 \mathrm{ng} \mathrm{mL}^{-1}\right)$ was added on day 7 . Although the addition of TNF- $\alpha$ to the culture one day prior to addition of DEX enhanced the differentiation of DCs (high percent of CD83 expressing DCs), TNF- $\alpha$ didn't affect the morphological changes of DCs which became mature 
Sci. Technol. Dev., 34 (2): 74-81, 2015
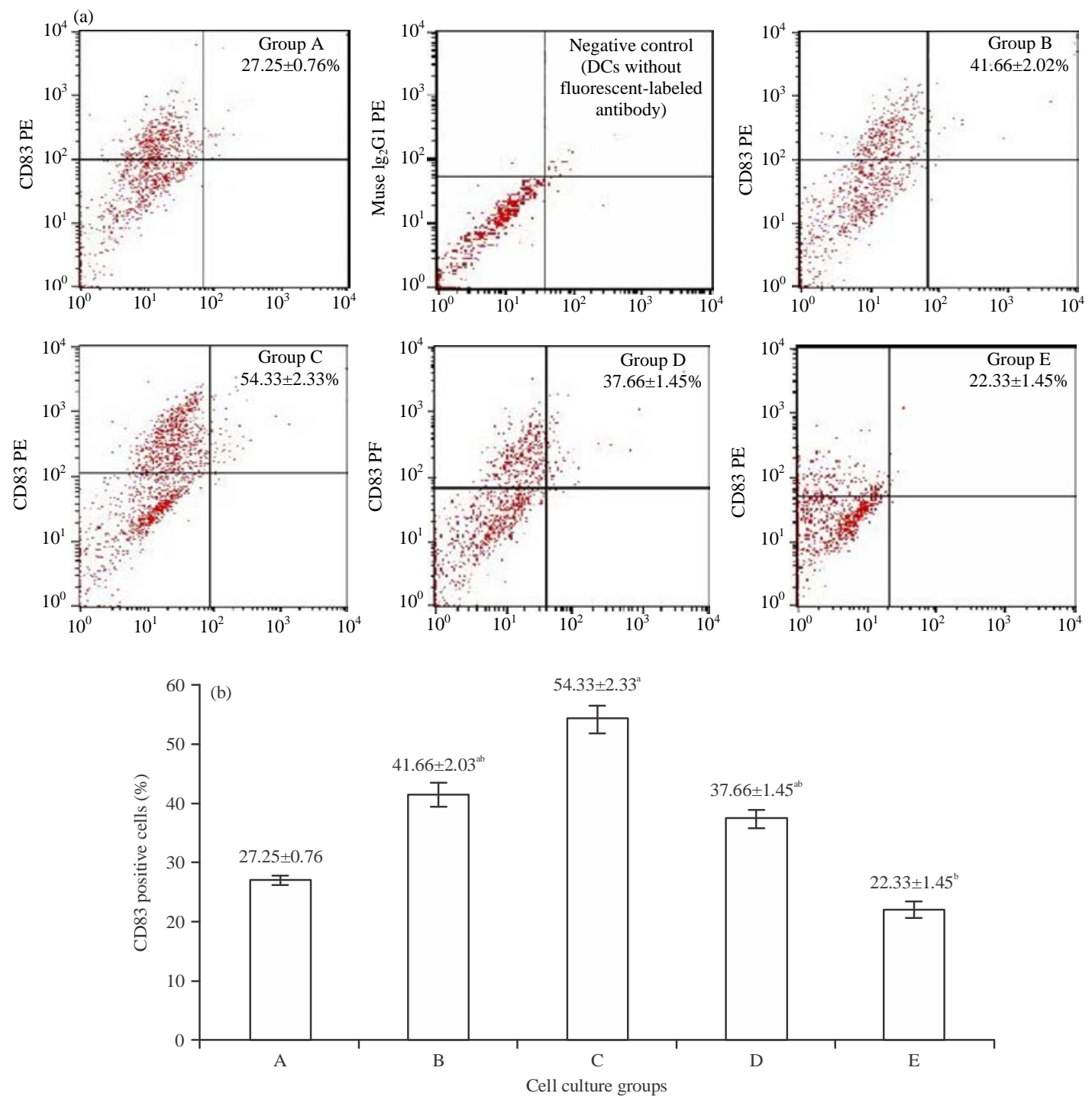

Fig. 3(a-b): Effect of DEX on CD83 expression in various cell cultures, (a) Flow cytometry showing the expression of CD83. Monocyte-derived DCs were generated in presence or absence of DEX. $1 \mu \mathrm{M}$ of DEX was added at different time points. (Group A) control group, (Group B) $1 \mu \mathrm{M}$ DEX on day 7, (Group C) TNF- $\alpha$ $\left(10 \mathrm{ng} \mathrm{mL}^{-1}\right)$ on day $7+1 \mu \mathrm{M}$ DEX on day 8 , (Group D) $1 \mu \mathrm{M}$ DEX on day 7+TNF- $\alpha\left(10 \mathrm{ng} \mathrm{mL}^{-1}\right)$ on day 8; (Group E) $1 \mu \mathrm{M}$ DEX on day 0+TNF- $\alpha\left(10 \mathrm{ng} \mathrm{mL}^{-1}\right)$ on day 7 and (b) Percentage of DCs expressing CD83 in different groups. Expression of CD83 cell marker was measured by BD FACSCalibur ${ }^{\circledR}$. Each value is the mean of 3 experiments \pm SE. a: Significant versus control group, b: Significant versus group C

even in the absence of TNF- $\alpha$. Our results were opposite to some previous studies which reported that TNF- $\alpha$ is a maturation factor essential for the appearance of the morphological characteristics of DCs (Brunner et al., 2000).

The CD83 is a surface marker that distinguishes immature and mature human dendritic cell populations (Prazma and Tedder, 2008). The CD83 is type 1 glycoprotein belonging to the immunoglobulin superfamily and has been known to be one of the best markers for characterization of cultured DCs. It was recorded that both stimulated DCs and B cells secrete soluble form of CD83 and so low concentration of soluble CD83 are present in normal human sera (Lechmann et al., 2002). The CD83 seems to possess regulatory roles for immune response. The soluble form of CD83 can repress immune responses, while being strongly up-regulated during DCs maturation and activation (Chen et al., 2011).

These results were consistent with Fujimoto and Tedder (2014), who revealed that CD83 has 

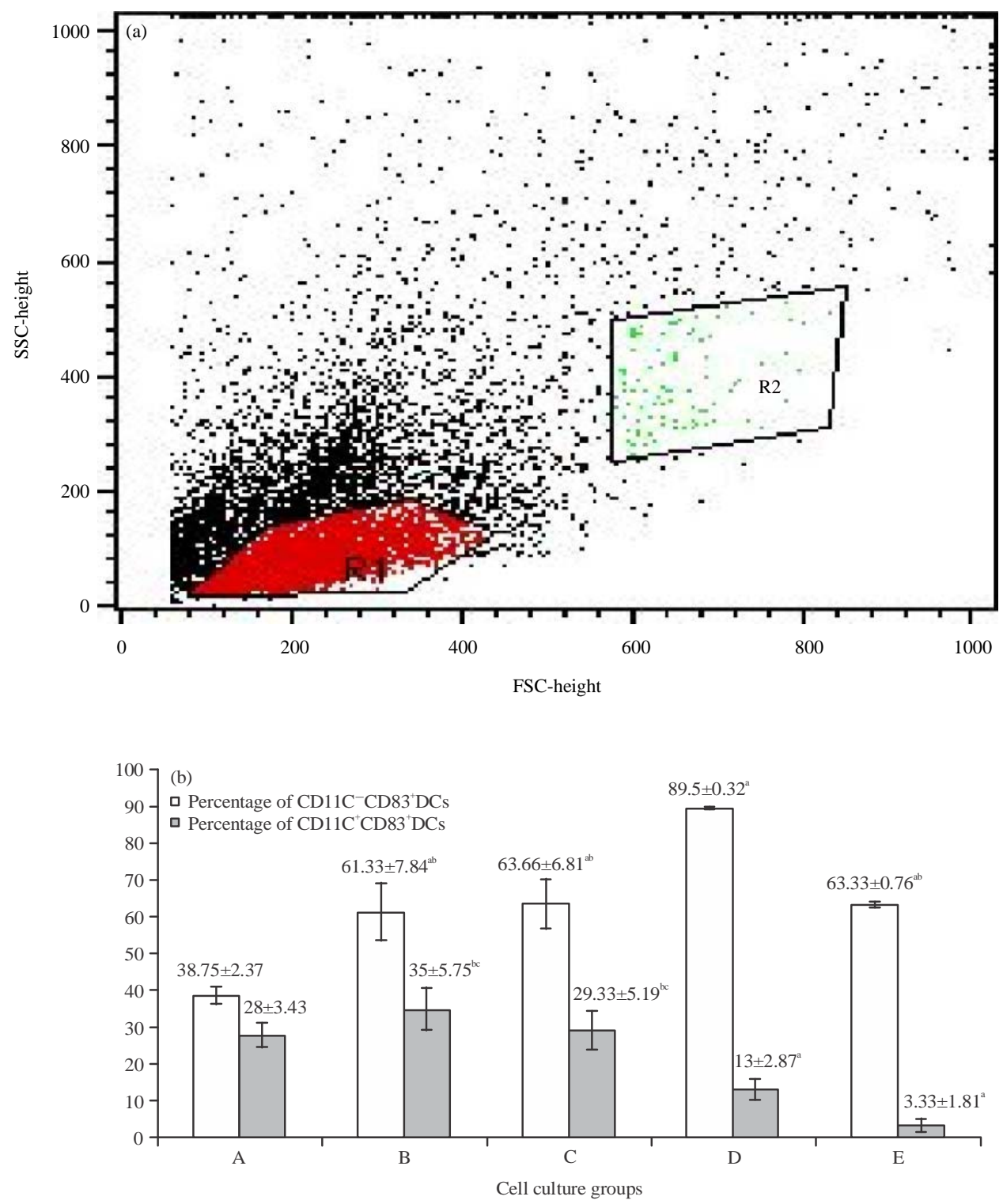

Fig. 4(a-b): Flow cytometric analysis of $\mathrm{CD} 11 \mathrm{c}^{-} \mathrm{CD} 83^{+}$and $\mathrm{CD} 11 \mathrm{c}^{+} \mathrm{CD} 83^{+}$expressing splenic DCs obtained from different animal groups, (a) Gates of $\mathrm{CD} 11 \mathrm{c}^{-} \mathrm{CD} 83^{+}$and $\mathrm{CD} 11 \mathrm{c}^{+} \mathrm{CD} 83^{+}$DCs. T cells and B cells (CD83 ${ }^{-}$) were gated out. Total CD11 $\mathrm{c}^{-} \mathrm{CD} 83^{+}$cells were gated by R1, whereas $\mathrm{CD} 11 \mathrm{c}^{+} \mathrm{CD} 83^{+}$population was gated by R2. FSC-Height refers to forward scattered light height. SSC-Height refers to side scattered pulse height and (b) Effect of DEX on the percentage of $\mathrm{CD} 11 \mathrm{c}^{-} \mathrm{CD} 83^{+}$and $\mathrm{CD} 11 \mathrm{c}^{+} \mathrm{CD} 83^{+}$expressing murine splenic DCs. (Group A) control group, (Group B) DEX (4.5 $\mathrm{mg} \mathrm{kg}^{-1}$, 5 days), (Group C) DEX (4.5 mg kg $\mathrm{kg}^{-1}$, 5 days)+TNF- $\alpha$ (5 $\mu \mathrm{g} \mathrm{kg}^{-1}$, single), (Group D) DEX (20 mg kg-1, single), (Group E) DEX (20 $\mathrm{mg} \mathrm{kg}^{-1}$, single)+TNF- $\alpha$ ( $5 \mu \mathrm{kg}^{-1}$, single). DEX and TNF- $\alpha$ were given i.p. Data is presented as mean $\pm \mathrm{SE}$. a: Significant versus corresponding control group A, b: Significant versus corresponding group D, c: Significant versus corresponding group E

immunosuppressive roles such as the inhibition of dendritic cell-mediated $\mathrm{T}$ cell stimulation. The immunosuppressant mechanisms of CD83 were illustrated by the study of Ge et al. (2010), who reported that CD83 is capable of down-modulating expression of various DC surface molecules, such as MHC-II, reducing the allogeneic stimulatory capacity of the DCs and significantly inhibiting anti-donor antibody responses. Present results were further supported by the study of Sanna et al. (2006), who reported that the elevated CD83 
expression suggests the possibility of DEX-generated cells to initiate a Th2-biased response where CD83 is able to inhibit DCs mediated T cells stimulation. Furthermore, Xia et al. (2005) reported that DEX treated DCs produce a large amount of IL-10 which can induce Tregs.

However, treatment of monocytes with DEX (day 0), herein, produced insignificant change in the percent of regulatory cell marker CD83 expression on DCs. These findings suggest that the time of exposure of DCs to DEX is critical for them to be tolerogenic. Our results could be supported by the work of Bosma et al. (2008), who reported that pretreatment of primary human blood DCs with DEX resulted in the generation and maturation of non-tolerogenic DCs with reduced CD83 expression.

In this study, in vivo experiments were performed to compare DEX effect on murine splenic DCs with the in vitro results. The effect of DEX on different subsets of splenic DCs in mice was examined through phenotypic analysis. In accordance with the results obtained in vitro, the in vivo experiment indicated that DEX treatment resulted in significant increase of the expression of CD83 on splenic DCs. Therefore, the action mechanism of DEX as an adjuvant on splenic DCs may be, in part, through upregulation of CD83 expression.

These results revealed that the combination of high dose DEX and TNF- $\alpha$ showed significant inhibition of percentage of $\mathrm{CD} 11 \mathrm{c}^{-} \mathrm{CD} 83^{+}$splenic DCs compared to single high dose DEX treatment only. These results suggest that TNF- $\alpha$ might play an important role in immuno-stimulation of splenic DCs, through the inhibition of expression of cell surface marker CD83. This result confirms the findings of a previous study that showed that low-dose of TNF- $\alpha$ increases the production of an immunostimulatory response to regulate innate immunity (Jiao et al., 2014).

The present results indicated that DEX depletes

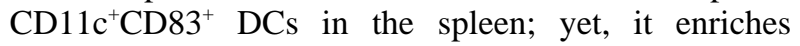
CD11 ${ }^{-}{ }^{-} D 83^{+}$DCs subset that functions as tolerogenic DCs, suggesting that DEX's adjuvant mechanism may involve in vivo selection of tolerogenic DCs. Moreover, our findings showed a complete decrease of percentage of

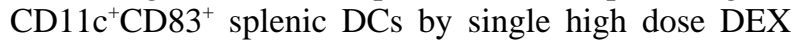
treatment which could be explained by that the immunosuppressant mechanisms of DEX, however, do not exclude the possibility of depletion of $\mathrm{CD} 11 \mathrm{c}^{+} \mathrm{CD} 83^{+}$ cells, thereby contributing to the tolerogenic effect of $\mathrm{DEX}$. If this is the case, depleting the $\mathrm{CD} 11 \mathrm{c}^{+} \mathrm{CD} 83^{+} \mathrm{DCs}$ during recall stimulation might dampen recall responses.

These results were consistent with Abe et al. (2005), who revealed that DEX might selectively deplete non-tolerogenic DCs in vivo, while maintaining tolerogenic DCs, that in turn contribute to the expansion of Ag-specific Treg. An additional support was provided by Zheng et al. (2013), who reported that DEX appears as a tolerogenic adjuvant notably by enhancing the tolerogenic APCs.

\section{CONCLUSION}

The present study revealed that plastic-adherent peripheral blood monocytes, when cultured with GM-CSF and IL-4 in autologous human plasma-supplemented media, comprise an efficient source of functional DCs that may be of value for human therapy. The DEX-induced immune tolerance could be, in part, through modulation of the expression of the DC specific cell markers. Further study of the immune-mediated mechanisms could be of value in preventing and managing major immune disorders.

\section{REFERENCES}

Abe, M., B.L. Colvin and A.W. Thomson, 2005. Plasmacytoid dendritic cells: In vivo regulators of alloimmune reactivity? Transplantation Proc., 37: 4119-4121.

Baschant, U. and J. Tuckermann, 2010. The role of the glucocorticoid receptor in inflammation and immunity. J. Steroid Biochem. Mol. Biol., 120: 69-75.

Bosma, B.M., H.J. Metselaar, N. Nagtzaam, R. de Haan and S. Mancham et al., 2008. Dexamethasone transforms lipopolysaccharide-stimulated human blood myeloid dendritic cells into myeloid dendritic cells that prime interleukin-10 production in T cells. Immunology, 125: 91-100.

Brunner, C., J. Seiderer, A. Schlamp, M. Bidlingmaier and A. Eigler et al., 2000. Enhanced dendritic cell maturation by TNF- $\alpha$ or cytidine-phosphateguanosine DNA drives $\mathrm{T}$ cell activation in vitro and therapeutic anti-tumor immune responses in vivo. J. Immunol., 165: 6278-6286.

Chen, L., Y. Zhu, G. Zhang, C. Gao, W. Zhong and X. Zhang, 2011. CD83-stimulated monocytes suppress T-cell immune responses through production of prostaglandin E2. Proc. Natl. Acad. Sci. USA., 108: 18778-18783.

Demangel, C., P. Bertolino and W.J. Britton, 2002. Autocrine IL-10 impairs dendritic cell (DC)-derived immune responses to mycobacterial infection by suppressing DC trafficking to draining lymph nodes and local IL-12 production. Eur. J. Immunol., 32: 994-1002.

Everts, B. and E.J. Pearce, 2014. Metabolic control of dendritic cell activation and function: Recent advances and clinical implications. Front. Immunol., Vol. 5. 10.3389/fimmu.2014.00203

Fletcher, A.L., T.E. Lowen, S. Sakkal, J.J. Reiseger and M.V. Hammett et al., 2009. Ablation and regeneration of tolerance-inducing medullary thymic epithelial cells after cyclosporine, cyclophosphamide and dexamethasone treatment. J. Immunol., 183: 823-831. 
Fujimoto, Y. and T.F. Tedder, 2014. CD83: A regulatory molecule of the immune system with great potential for therapeutic application. J. Med. Dental Sci., 53: 85-91.

Ge, W., J. Arp, D. Lian, W. Liu and M.L. Baroja et al., 2010. Immunosuppression involving soluble CD83 induces tolerogenic dendritic cells that prevent cardiac allograft rejection. Transplantation, 90: 1145-1156.

Gelao, L., C. Criscitiello, A. Esposito, M.D. Laurentiis and L. Fumagalli et al., 2014. Dendritic cell-based vaccines: Clinical applications in breast cancer. Immunotherapy, 6: 349-360.

Gustafson, M.P., Y. Lin, K.C. New, P.A. Bulur and B.P. O'Neill et al., 2010. Systemic immune suppression in glioblastoma: The interplay between CD14 ${ }^{+}$HLA-DRlo/neg monocytes, tumor factors and dexamethasone. Neuro-Oncology, 12: 631-644.

Hashimdeen, S.S., A. Romhild, M. Schmueck, K. Kratz, A. Lendlein, A. Kurtz and P. Reinke, 2013. Culture surface influence on T-cell phenotype and function. Clin. Hemorheol. Microcirculation, 55: 501-512.

Hilkens, C.M.U., J.D. Isaacs and A.W. Thomson, 2010. Development of dendritic cell-based immunotherapy for autoimmunity. Int. Rev. Immunol., 29: 156-183.

Jiao, S.F., K. Sun, X.J. Chen, X. Zhao and N. Cai et al., 2014. Inhibition of tumor necrosis factor alpha reduces the outgrowth of hepatic micrometastasis of colorectal tumors in a mouse model of liver ischemia-reperfusion injury. J. Biomed. Sci., Vol. 21.

Kadowaki, N., S. Ho, S. Antonenko, R. de Waal Malefyt, R.A. Kastelein, F. Bazan and Y.J. Liu, 2001. Subsets of human dendritic cell precursors express different toll-like receptors and respond to different microbial antigens. J. Exp. Med., 194: 863-870.

Kalantari, T., E. Kamali-Sarvestani, B. Ciric, M.H. Karimi and M. Kalantari et al., 2011. Generation of immunogenic and tolerogenic clinical-grade dendritic cells. Immunol. Res., 51: 153-160.

Lechmann, M., S. Berchtold, A. Steinkasserer and J. Hauber, 2002. CD83 on dendritic cells: More than just a marker for maturation. Trends Immunol., 23: 273-275.

Moresco, E.M.Y., D. LaVine and B. Beutler, 2011. Toll-like receptors. Curr. Biol., 21: R488-R493.

Nakano, H., M. Yanagita and M.D. Gunn, 2001. $\mathrm{CD} 11 \mathrm{c}^{+} \mathrm{B} 220^{+} \mathrm{Gr}-1^{+}$cells in mouse lymph nodes and spleen display characteristics of plasmacytoid dendritic cells. J. Exp. Med., 194: 1171-1178.
Prazma, C.M. and T.F. Tedder, 2008. Dendritic cell CD83: A therapeutic target or innocent bystander? Immunol. Lett., 115: 1-8.

Rubinstein, M.P., A.N. Kadima, M.L. Salem, C.L. Nguyen, W.E. Gillanders and D.J. Cole, 2002. Systemic administration of IL-15 augments the antigen-specific primary $\mathrm{CD8}^{+} \mathrm{T}$ cell response following vaccination with peptide-pulsed dendritic cells. J. Immunol., 169: 4928-4935.

Saito, M., M. Nagasawa, H. Takada, T. Hara and S. Tsuchiya et al., 2011. Defective IL-10 signaling in hyper-IgE syndrome results in impaired generation of tolerogenic dendritic cells and induced regulatory $\mathrm{T}$ cells. J. Exp. Med., 208: 235-249.

Sanna, A., M.L. Fois, G. Arru, Y.M. Huang and H. Link et al., 2006. Glatiramer acetate reduces lymphocyte proliferation and enhances IL-5 and IL-13 production through modulation of monocyte-derived dendritic cells in multiple sclerosis. Clin. Exp. Immunol., 143: 357-362.

Stein, M.F., S. Lang, T.H. Winkler, A. Deinzer and S. Erber et al., 2013. Multiple interferon regulatory

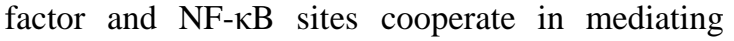
cell-type- and maturation-specific activation of the human CD83 promoter in dendritic cells. Mol. Cell. Biol., 33: 1331-1344.

Stetler-Stevenson, M. and R.C. Braylan, 2001. Flow cytometric analysis of lymphomas and lymphoproliferative disorders. Seminars Hematol., 38: 111-123.

Trombetta, E.S. and I. Mellman, 2005. Cell biology of antigen processing in vitro and in vivo. Ann. Rev. Immunol., 23: 975-1028.

Wang, J., L. Su and T. Zhu, 2013. Effect of dendritic cells on the differentiation of Th1/Th17 in peripheral blood from preeclampsia patients. Chin. J. Cell. Mol. Immunol., 29: 744-747.

Xia, C.Q., R. Peng, F. Beato and M.J. Clare-Salzler, 2005. Dexamethasone induces IL-10-producing monocyte-derived dendritic cells with durable immaturity. Scand. J. Immunol., 62: 45-54.

Ye, Z., Z. Chen, A. Sami, A. El-Gayed and J. Xiang, 2006. Human dendritic cells engineered to express alpha tumor necrosis factor maintain cellular maturation and T-cell stimulation capacity. Cancer Biotherapy Radiopharm., 21: 613-622.

Zheng, G., S. Zhong, Y. Geng, G. Munirathinam and I. Cha et al., 2013. Dexamethasone promotes tolerance in vivo by enriching $\mathrm{CD} 11 \mathrm{c}^{\mathrm{lo}} \mathrm{CD} 40^{\mathrm{lo}}$ tolerogenic macrophages. Eur. J. Immunol., 43: 219-227. 